\title{
A Study of Electrochemical Behavior for Redox Current Peaks of Sodium Saccharin at Different Temperature Using Nano-Sensor
}

\author{
Muhammed Mizher Radhi ${ }^{1, ~}$, Yousif A. Kadium², Anfal Ismael Ibrahim ${ }^{2}$ \\ ${ }^{1}$ Radiological Techniques Department, Health and Medical Technology College-Baghdad, Middle Technology University, Baghdad, Iraq \\ ${ }^{2}$ Chemistry Department, Science College, Al-Mustansiriyah University, Baghdad, Iraq
}

Email address:

mmradhi@yahoo.com (M. M. Radhi)

${ }^{*}$ Corresponding author

\section{To cite this article:}

Muhammed Mizher Radhi, Yousif A. Kadium, Anfal Ismael Ibrahim. A Study of Electrochemical Behavior for Redox Current Peaks of Sodium Saccharin at Different Temperature Using Nano-Sensor. European Journal of Clinical and Biomedical Sciences.

Vol. 3, No. 2, 2017, pp. 47-52. doi: 10.11648/j.ejcbs.20170302.12

Received: January 25, 2017; Accepted: February 24, 2017; Published: April 25, 2017

\begin{abstract}
The study of Sodium Saccharin (NaSc), this one of the chemical compounds was used as a replacement for natural sugar, which taking by diabetic patients. $\mathrm{NaSc}$ was studied by cyclic voltammetric technique to analysis at different temperature using modified glassy carbon electrode (GCE) with carbon nanotubes (CNT) as working electrode (CNT/GCE). Activation energy $\left(\mathrm{E}_{\mathrm{a}}^{*}\right)$ of NaSc was studied in $1 \mathrm{M} \mathrm{Na}_{2} \mathrm{SO}_{4}$ as an electrolyte at different temperature using Arrhenius equation at both GCE and CNT/GCE. Other thermodynamic parameters such as activation free energy $\left(\Delta \mathrm{G}^{*}\right)$, activation enthalpy $\left(\Delta \mathrm{H}^{*}\right)$ and activation entropy $\left(\Delta \mathrm{S}^{*}\right)$ were determined at both GCE and CNT/GCE using Eyring equation. Other thermodynamic parameters such as the values of entropy for cathodic current peak of NaSc on GCE and CNT/GCE are positive value, this means that the reaction is spontaneous reversible, but the negative values of entropy is irreversible reaction.
\end{abstract}

Keywords: Sodium Saccharin, Nano-Sensor, Cyclic Voltammetry, Different Temperature, Thermodynamic Parameters, Non-aqueous Electrolyte

\section{Introduction}

Sodium saccharin (NaSc) a chemical compounds that is used as a sugar substitute about 300-400 times as sweet as sucrose or table sugar, but this chemical compound may be affecting on human health. The earlier studies were done on mice which have given dangerous results with the development of bladder cancer $[1,2]$.

For the importance of this subject which attachment with human health in terms of nutrition, it has been studied using the electrochemical method to know the behavior of the redox properties in blood medium and discuss the effect on the blood composition. NaSc (1,2-Benzisothiazol-3(2H)-one, 1,1-dioxide, sodium salt) was listed as known to the state to cause cancer under Proposition 65 on 1988 [3, 4].

Saccharin was used in various medical fields which has been ability to coordinate from one, two or three side with another metal [5]. Iron with saccharin may be causes a complex and affected on the composition of the ironsaccharin [6]. In addition to the iron ions which is the main component of blood. Cyclic voltammetry is useful in the study of the behavior of redox active electrical species was chosen in this study due to giving the information on the reduction and oxidation current peaks in blood medium [7-9].

Some studies explain the mechanism of converted Saccharin to its more nucleophilic sodium salt as shown in the scheme 1 [10]:
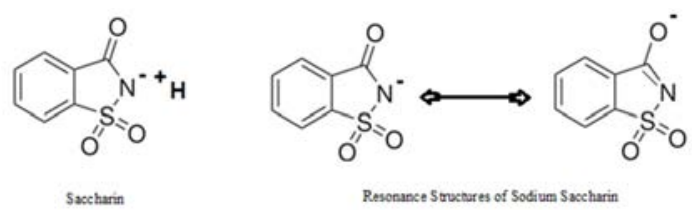

Scheme 1. Structure of saccharin and sodium saccharin.

In this work, NaSc was studied at different temperature using nano-sensor to analysis the redox current peaks and determination each of thermodynamic functions and 
activation energy in $1 \mathrm{M} \mathrm{Na}_{2} \mathrm{SO}_{4}$ as an electrolyte.

\section{Experiment}

\subsection{Materials}

Sodium saccharin (purity $98 \%$ from china company), carbon nanotubes (purity 99\%) supplied from Fluka company (Germany), $\mathrm{Na}_{2} \mathrm{SO}_{4}$ in high purity materials from SCRC (china). Deionize water was used for preparation of aqueous solutions. All solutions which used in the cyclic voltammetryic cell were treated with nitrogen gas for 10-15 minutes prior to oxygen free from the solutions.

\subsection{Apparatus}

The instrument EZstat series (Potentiostat/Glvanostat) NuVant Systems Inc (made in USA) was used in all experiments. The Electrochemical Bio-analytical cell was connected with potetio-state device and monitoring through the special program that has been installed on the personal computer to perform cyclic voltammetry $(\mathrm{CV})$. The silversilver chloride reference electrode $(\mathrm{Ag} / \mathrm{AgCl}$ in $3 \mathrm{M} \mathrm{NaCl})$ and Platinum wire (1 $\mathrm{mm}$ diameter) was used as a reference and counter electrodes respectively. The glassy carbon working electrode (GCE) modified with CNT was used in this study after cleaning with alumina solution and treated with ultrasonic path water for ten minutes.

\subsection{Preparing the Modified Working Electrode GCE with CNT (CNT/GCE)}

The mechanical attachment technical method to prepare the CNT/GCE working electrode was employed to preparation of nano-sensor [11, 12]. The method of the modification of GCE included abrasive application of multiwall carbon nanotubes (MWCNT) on the clean surface of GCE, forming an array of MWCNT as modified working electrode MWCNT/GCE and replaced in $10 \mathrm{ml}$ of electrolyte in the cyclic voltammetric cell, then connected all electrodes (working electrode, reference electrode and counter electrode) with the potentio-state.

\subsection{Measurements of Different Temperatures}

It has been using a cell measuring of cyclic voltammogram size $10 \mathrm{ml}$ and replaces the solution which required for studying at different temperatures, and then submerged in it three electrodes (working, reference and counter electrodes) as well as the thermometer to measure the degree of the temperature of study solution, and then connect the three electrodes with the potentio-stat. The cell placed in a water bath to install the required temperature and can be used regular hot plate to increasing the temperatures.

\section{Results and Discussion}

\subsection{Enhancement of Redox Current Peaks of NaSc Using Different Electrolytes}

In previous study of the effect different supporting electrolytes on redox current peaks of $\mathrm{NaSc}$ in each of $\mathrm{KCl}$, Normal saline $\mathrm{NaCl} 0.9 \%$ (NS), $\mathrm{KH}_{2} \mathrm{PO}_{4}, \mathrm{Na}_{2} \mathrm{SO}_{4}, \mathrm{KClO}_{4}$, $\mathrm{K}_{2} \mathrm{SO}_{4}$ and $\mathrm{KNO}_{3}$ were determined by analytical electrochemical method using cyclic voltammetry. It was found that the solution of $\mathrm{NaSc}$ in $1 \mathrm{M} \mathrm{Na} \mathrm{Na}_{2} \mathrm{SO}_{4}$ has been enhanced the oxidation-reduction current peaks among of these electrolytes, so it can be used as a good supporting electrolyte in this study at room temperature $\left(25^{\circ} \mathrm{C}\right)$.

\subsection{Effect varying Temperature}

\subsubsection{Study the Activation Energy}

The effect of temperature on the oxidation- reduction process of $\mathrm{NaSc}$ in $1 \mathrm{M} \mathrm{Na}_{2} \mathrm{SO}_{4}$ was studied to determination the activation energy $\left(\mathrm{Ea}^{*}\right)$ using GCE and $\mathrm{CNT} / \mathrm{GCE}$ as working electrodes at different temperatures. The oxidation current peak $\left(I_{\mathrm{pa}}\right)$ of the NaSc has been enhanced gradually against to increasing the temperature at the range from 1 to $54^{\circ} \mathrm{C}$ as shown in table 1 . Figure 1 and 2 represent in plot of $\ln \left(\mathrm{I}_{\mathrm{pa}}\right)$ of NaSc versus reciprocal of temperature on GCE and CNT/GCE electrodes, respectively which is found to be linear in agreement with thermodynamic expectation of Arrhenius equations 1 and 2 [13].

$$
\begin{aligned}
& \sigma=\sigma^{\circ} e^{-\mathrm{E}^{*} / \mathrm{RT}} \\
& \mathrm{D}=\mathrm{D}^{\circ} \mathrm{e}^{-\mathrm{Ea} / \mathrm{RT}}
\end{aligned}
$$

Where

$\mathrm{E}_{\mathrm{a}}^{*}$ - activation energy

$\mathrm{R}$ - universal gas constant

$\mathrm{T}$ - temperature

$\sigma / \mathrm{D}=$ conductivity $/$ diffusibility .

$\sigma^{\circ} \mathrm{D}^{\circ}=$ standard conductivity/ initial diffusibility.

From the slope of linear relationship the value of activation energy of oxidation current peak of $\mathrm{NaSc}$ is $\mathrm{Ea}^{*}{ }_{\mathrm{pa}}=17.056$ $\mathrm{kJ} / \mathrm{mol}$. K on GCE (Figure 1) and $\mathrm{Ea}^{*}{ }_{\mathrm{pa}}=15.029 \mathrm{~kJ} / \mathrm{mol}$. K on CNT/GCE (Figure 2). The finding results show that the activation energy was decreased in values when using modified electrode CNT/GCE which act electro-catalyst in electrolyte. The same results was found in the reduction current peak, the values of $\mathrm{Ea}^{*}{ }_{\mathrm{pc}}$ is $12.711 \mathrm{~kJ} / \mathrm{mol}$. $\mathrm{K}$ at CNT/GCE (Figure 3) and $\mathrm{Ea}_{\mathrm{pc}}$ is $14.321 \mathrm{~kJ} / \mathrm{mol}$. K at GCE (Figure 4) as shown in table 1. The conductivity of CNT with increasing temperature also plays a signification influence on the activation energy for diffusion of the substrate of interest [14].

\begin{tabular}{|c|c|c|c|c|c|c|}
\hline Type of Reaction & Working Electrode & $\Delta \mathrm{G}^{*} \mathrm{~kJ} / \mathrm{mol}$ & $\Delta \mathrm{H}^{*} \mathrm{~kJ} / \mathrm{mol}$ & $\Delta \mathrm{S} * \mathbf{k} / \mathbf{J m o l}$ & Ea* kJ/mol & Reaction status \\
\hline reduction & GCE & -57.840 & -2.505 & +0.183 & +14.321 & spontaneous reaction \\
\hline reduction & $\mathrm{CNT} / \mathrm{GCE}$ & -57.864 & -2.489 & +0.184 & +12.711 & spontaneous reaction \\
\hline oxidation & GCE & +59.382 & -2.481 & -0.205 & +17.056 & nonspontaneous reaction \\
\hline
\end{tabular}

Table 1. Activation energy and thermodynamic functions of NaSc in $1 M \mathrm{Na}_{2} \mathrm{SO}_{4}$ at GCE and CNT/GCE. 


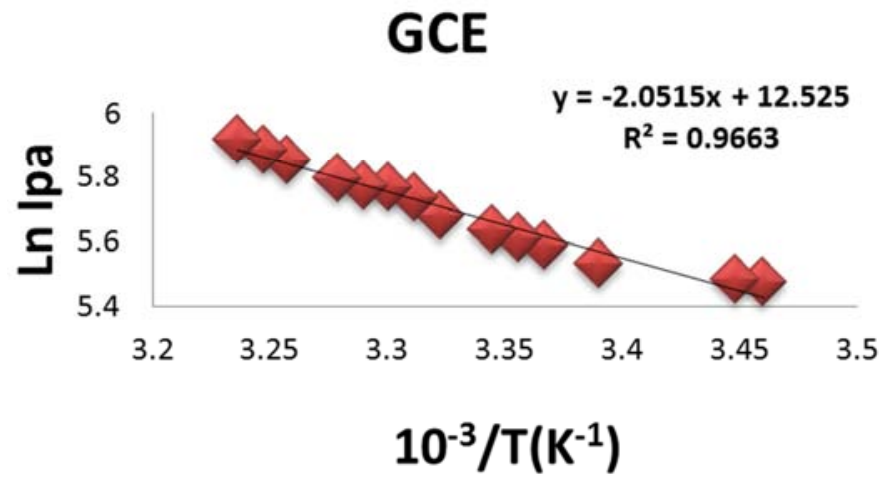

Figure 1. Plot of Ln (I $\mathrm{I}_{p a}$ oxidation current peak of $0.001 \mathrm{mM} \mathrm{NaSc}$ in $\mathrm{Na}_{2} \mathrm{SO}_{4}$ against to inverse temperature at GCE versus $\mathrm{Ag} / \mathrm{AgCl}$ as reference electrode.

\section{CNT/GCE}

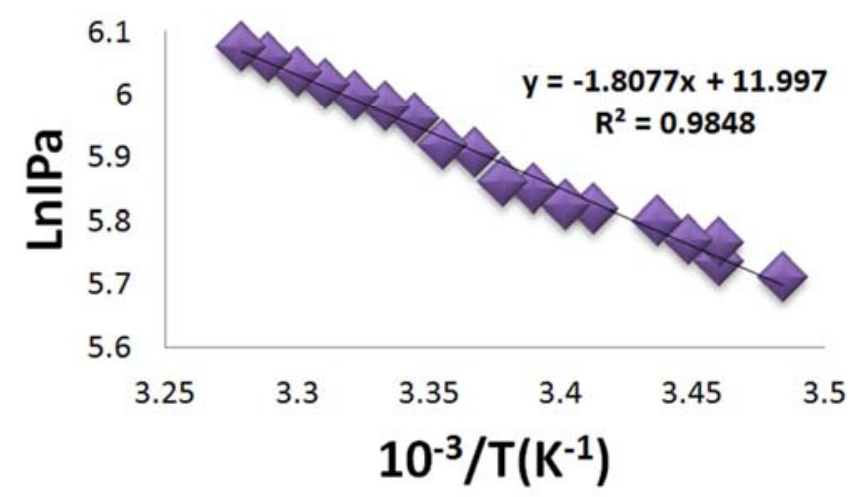

Figure 2. Dependence of oxidation current of Sodium saccharin as function of Temperature at CNT/GCE versus $\mathrm{Ag} / \mathrm{AgCl}$.

\section{CNT/GCE}

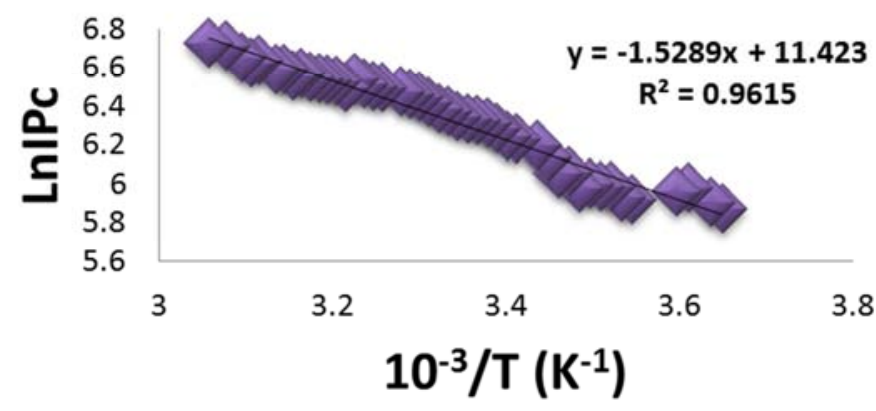

Figure 3. Dependence of reduction current of Sodium saccharin as function of Temperature at CNT/GCE versus Ag/AgCl.

\section{GCE}

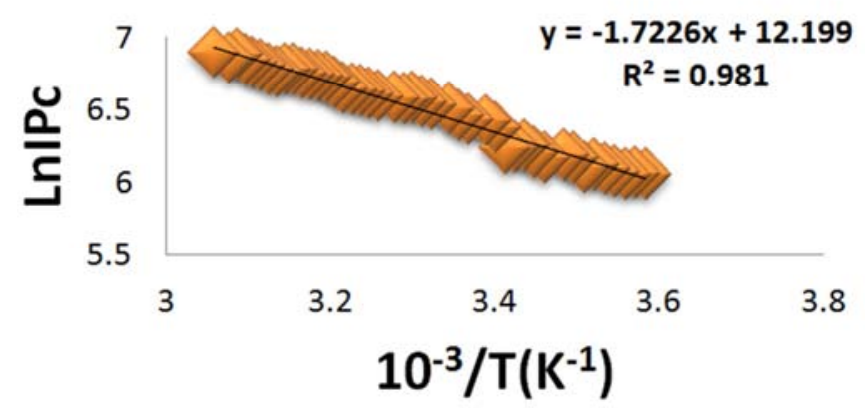

Figure 4. Dependence of reduction current of Sodium saccharin as function of Temperature at GCE electrode versus $\mathrm{Ag} / \mathrm{AgCl}$. 


\subsubsection{Effect the High Temperature on Redox of NaSc at Different Electrodes}

In electrochemical studies the modified electrodes with nano-particles (nano sensors) acts as electro-catalyst by decreasing the activation energy of redox current peaks of $\mathrm{NaSc}$ in electrolyte. But high temperatures act to decreasing the conductivity at the electrode which impedes the diffusion of the ions in the electrolyte on both oxidation and reduction peaks on modified and non-modified working electrode as shown in Figure 5 and 6 [15], also the Figures show that an increase in temperature 1 and $54^{\circ} \mathrm{C}$ is accompanied by an increase in current on $\mathrm{CNT} / \mathrm{GCE}$ and GCE electrode, and causes shifting of reduction potential towards origin and in a negative direction. Evidently, simultaneous application on the use of CNT, and temperature increase, exerting electro catalytic effect [16] and thermal effect respectively leads to a much higher current enhancement as observed.

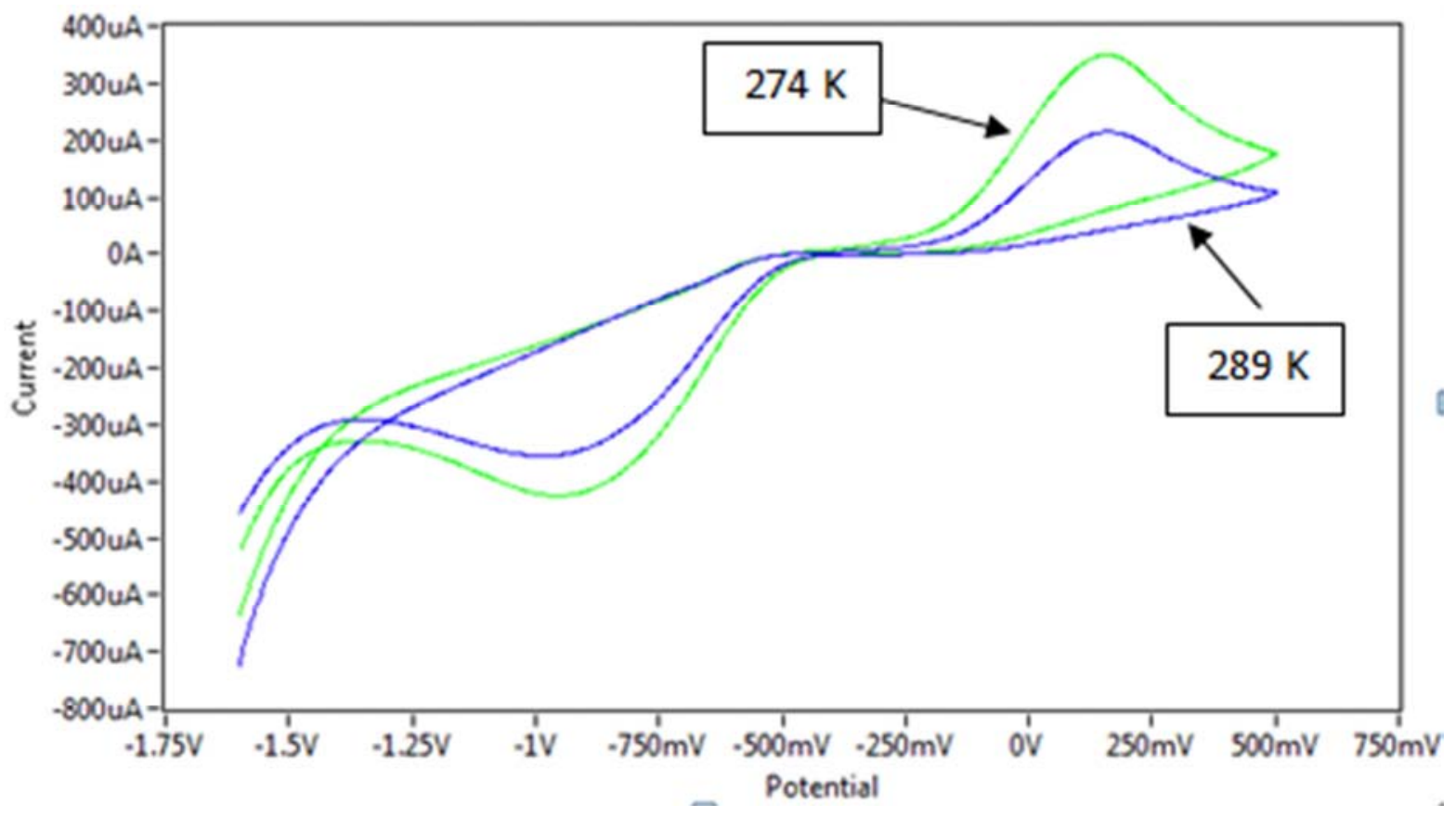

Figure 5. Cyclic voltammogram of sodium saccharin in $\mathrm{Na}_{2} \mathrm{SO}_{4}$ at $274 \mathrm{~K}$ and $289 \mathrm{~K}$ on $\mathrm{CNT/GCE}$.

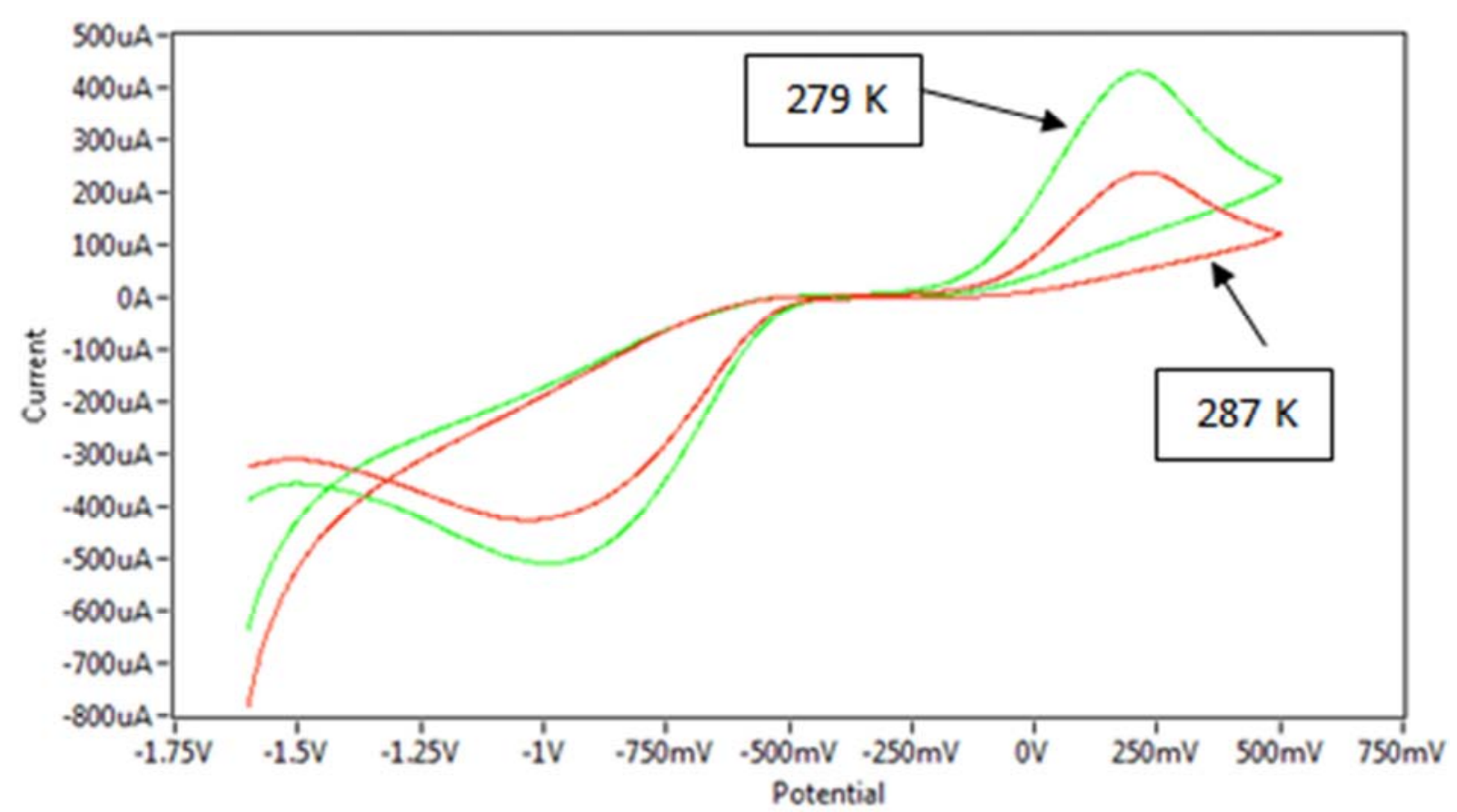

Figure 6. Cyclic voltammogram of sodium saccharin in $\mathrm{Na}_{2} \mathrm{SO}_{4}$ at $279 \mathrm{~K}$ and $287 \mathrm{~K}$ on $\mathrm{GCE}$. 


\subsubsection{Thermodynamic Functions}

It can be get all thermodynamic functions through the developments conclusions between thermodynamic equations [17] and electrochemical equations using Eyring equation [18-20] and with activation energy by Arrhenius equations [13] to calculation all thermodynamic functions such as activation free energy $\left(\Delta \mathrm{G}^{*}\right)$, activation enthalpy $\left(\Delta \mathrm{H}^{*}\right)$ and activation entropy $\left(\Delta S^{*}\right)$ :

$$
\Delta \mathrm{G}^{*}=-\mathrm{RT} \operatorname{Ln}\left(\mathrm{k} \mathrm{h} / \mathrm{T} \mathrm{k} \mathrm{B}_{\mathrm{B}}\right.
$$

Eyring equation

$$
\begin{gathered}
\Delta \mathrm{H}^{*}=\Delta \mathrm{G}^{*}+\mathrm{T} \Delta \mathrm{S}^{*} \\
\text { And } \Delta \mathrm{H}^{*}=\Delta \mathrm{G}^{*}+\mathrm{T} \Delta \mathrm{S}^{*}
\end{gathered}
$$

The different units are accounted for in using either the gas

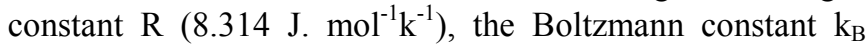
$\left(1.381 \times 10^{-23} \mathrm{~m}^{2} \mathrm{~kg} . \mathrm{sec}^{-2} \mathrm{k}^{-1}\right)$, and Plank constant $\mathrm{h}\left(6.66 \times 10^{-}\right.$

${ }^{34} \mathrm{~J}$. sec.) as the multiplier of temperature $\mathrm{T}(\mathrm{K})$.

In table (1) represent the values of activation free energy, activation enthalpy and activation entropy of oxidationreduction current peaks of $\mathrm{NaSc}$ in $\mathrm{Na}_{2} \mathrm{SO}_{4}$ medium on each of GCE and modified electrode CNT/GCE which shows the negative values of activation free energy for reduction reaction and positive values for oxidation reaction at both electrodes (GCE and $\mathrm{CNT} / \mathrm{GCE}$ ), the negative values of $\Delta \mathrm{G}^{*}$ mean the process of reduction is spontaneous reaction and the oxidation process is nonspontaneous reaction [21]. While the activation enthalpy $\left(\Delta \mathrm{H}^{*}\right)$ values are less than zero as shown in table 1 , that the negative values of $\Delta \mathrm{H}^{*}$ means the oxidation-reduction reaction of the $\mathrm{NaSc}$ are exothermic reaction, also the negative values of $\Delta S^{*}$ for oxidation process explain that the entropy which is a measure of the disorder, and the higher the entropy of a system, the lower the order of that system, so the positive values of reduction process with high order structure of $\mathrm{NaSc}$ according to the thermodynamic properties [22, 23].

\section{Conclusion}

The effect of different temperature on redox current peaks of $\mathrm{NaSc}$ in $\mathrm{Na}_{2} \mathrm{SO}_{4}$ as supporting electrolyte was studied at different electrodes (GCE and CNT/GCE) in cyclic voltammetric method to determination of thermodynamic functions using Eyring equation and activation energy by Arrhenius equations. It was found that $\mathrm{NaSc}$ compound has oxidation - reduction current peaks at the GCE and enhanced at CNT/GCE especially when using different temperatures. The redox process of $\mathrm{NaSc}$ in $\mathrm{Na}_{2} \mathrm{SO}_{4}$ was adopted on the values of thermodynamic functions which determined by the Eyring equations, that the reduction process of $\mathrm{NaSc}$ acts as spontaneous reaction in the electrolyte and nonspontaneous reaction at the oxidation process in both electrodes (GCE and $\mathrm{CNT} / \mathrm{GCE}$ ). Also, it was found the values of activation energy of NaSc which determined from Arrhenius equations has high value at GCE and low at modified electrode CNT/GCE because the nanoparticles of CNT on the surface of GCE acts as electro catalyst. Thermodynamic functions have not effected with the electrode, but the spontaneously of the oxidation-reduction reaction was depended on the these functions.

\section{References}

[1] Conis, Elena. Saccharin's mostly sweet following, Los Angeles Times, 2010.

[2] Weihrauch MR, Diehl V (2004). Artificial sweeteners, do they bear a carcinogenic risk, Ann Oncol. 15 (10): 1460-5.

[3] Gail Krowech, John B. Faust, Brian Endlich, Evidence on the carcinogenicity of sodium saccharin, 2002, USA.

[4] Diane, Report on Carcinogens (12th Ed. ), Amazon.com, 2011.

[5] A. H. Kibbe, Handbook of Pharmaceutical Excipients. London, UK (2000).

[6] F. Negro, Hepatotoxicity of saccharin. N. Engl. J. Med. 331: 134-5(1994).

[7] Kw. M. A., U. K. R. Malik, Romman and S. Z. Haider. Synthesis, Characterization and Properties of Some Complexes of Saccharin with Some Alkali Metals. J. Bangladesh Chem. Soc.12(1): 35 (1999).

[8] Romman, U. K. R., K. M. A. Malik and S. Z. Haider. 1999. Synthesis, Characterization and Properties of some Saccharine Complex Containing 1,10-phenanthroline as Secondary Ligand. J. Bangladesh Chem. Soc. 6(1): 43-50.

[9] Romman, U. K. R., K. M. A. Malik and S. Z. Haider. 1999. Synthesis, Characterization and Properties of some Saccharine Complex Containing 2,2'-bipyridine as Secondary Ligand. $J$. Bangladesh Acad. Sci. 23(2): 155.

[10] Zubrick, J. W. The Organic Chem Lab Survival Manual, 4th edition, Wiley \& Sons, Inc., New York, 1997.

[11] F, Scholz Lange B, Abrasive stripping voltammetry - an electrochemical solid state spectroscopy of wide applicability, Trends in Analytical Chemistry, 1992, 11, 359-367.

[12] Tan WT, Ng GK, Bond AM, Electrochemical of microcrystalline tetrathiafulvalene at an electrode solid aqueous KBr interface, Malaysian J. Chem. 2, 2000, 2; 34-42.

[13] Tan, W. T., and Lim E., Bond A. voltammetric studies on microcrystalline $\mathrm{C}_{60}$ adhered to an electrode surface by solvent casting and mechanical transfer methods. Journal Solid state Electrochemical 7: p 134-140 (2003).

[14] W. Tan, M. Radhi, M. Ab Rahman and A. Kassim, Electrochemical Reduction of Manganese Mediated by Carbon Nanotubes/Li+ Modified Glassy Carbon Electrodes, Asian Journal of Chemistry; Volume: 23 Issue: 6 Page: 2401 2406 (2011).

[15] A. Bard and L., Faulkner Electrochemical Methods: Fundamentals and Applications, Wiley, New York, end. 2 (2001).

[16] Ding, K. Q. cyclic Voltammetrically Prepared CopperDecorated $\mathrm{MnO}_{2}$ and its Electrochemical for Oxygen Reduction Reaction. International Journal of Electrochemical Science 5: $72-87$ (2010). 
[17] Farrington, D., Robert, and A. A., Physical Chemistry, John Wiley \& Sons Inc; 6th edition (1984).

[18] Evans, M. G., and Polanyi, M. (1935). Trans. Far. Soc., 31: 875-894.

[19] Polanyi, J. C., (1987), Science, 236 (4802): 680-690.

[20] Chapman, S., and Cowling, T. G., The Mathematical Theory of Non-uniform Gases: An Account of the Kinetic Theory of Viscosity, Thermal Conduction and Diffusion in Gases" (3rd Edition). Cambridge University Press, 1991
[21] Margaret M. Kane, Jocelyn M. Newhouse and Donald R. Sadoway, Electrochemical Determination of the Thermodynamic Properties of Lithium-Antimony Alloys, J. Electrochem. Soc. 2015 volume 162, issue 3, A421-A425.

[22] Eslami M, Zare HR, Namazian M, Thermodynamic parameters of electrochemical oxidation of L-DOPA: experimental and theoretical studies, J Phys Chem B. (2012) $18 ; 116(41): 12552-7$.

[23] Stoner, Clinton D., Inquiries into the Nature of Free Energy and Entropy in Respect to Biochemical Thermodynamics Entropy, Vol. 2. (2000). 